Article

\title{
Prevalence of Findings in Routine Abdominal Ultrasound in Patients with Systemic Autoimmune Rheumatic Diseases and Their Impact on Therapeutic Decision Making
}

\author{
Katharina Weiß ${ }^{1}$, Wolfgang A. Schmidt ${ }^{1}$, Andreas Krause ${ }^{1}$ and Valentin S. Schäfer ${ }^{2, *(D)}$ \\ 1 Department of Rheumatology and Clinical Immunology Berlin-Buch, Immanuel Krankenhaus Berlin, \\ 13125 Berlin, Germany; weiss-k@hotmail.com (K.W.); wolfgang.schmidt@immanuelalbertinen.de (W.A.S.); \\ andreas.krause@immanuelalbertinen.de (A.K.) \\ 2 Clinic for Internal Medicine III, Oncology, Haematology, Rheumatology and Clinical Immunology, University \\ Hospital Bonn, 53127 Bonn, Germany \\ * Correspondence: valentin.s.schaefer@hotmail.de
}

Citation: Weiß, K.; Schmidt, W.A.; Krause, A.; Schäfer, V.S. Prevalence of Findings in Routine Abdominal Ultrasound in Patients with Systemic Autoimmune Rheumatic Diseases and Their Impact on Therapeutic Decision Making. Appl. Sci. 2022, 12, 851. https://doi.org/10.3390/ app12020851

Received: 16 October 2021 Accepted: 11 January 2022

Published: 14 January 2022

Publisher's Note: MDPI stays neutral with regard to jurisdictional claims in published maps and institutional affiliations.

Copyright: (C) 2022 by the authors. Licensee MDPI, Basel, Switzerland. This article is an open access article distributed under the terms and conditions of the Creative Commons Attribution (CC BY) license (https:// creativecommons.org/licenses/by/ $4.0 /)$.

\begin{abstract}
Patients with systemic autoimmune rheumatic diseases (SARD) often receive abdominal ultrasound examinations to screen for organ involvement; yet, the spectrum of findings and their clinical relevance are poorly understood. We conducted a retrospective chart review of inpatients from a rheumatological referral centre with an abdominal ultrasound between 1 January2006 and 31 December 2015, examining 1092 SARD patients with a total of 1695 inpatient stays. The mean age was 55.1 years (range: 17-90 years, SD: 15.8), and the mean disease duration was 6.4 years (range: $0.0-52.8$ years, SD: 9.1 ). A total of $87.5 \%$ of the patients were female. The most frequent ultrasound findings were hepatic steatosis (in $26.8 \%$ of all patients), splenomegaly (15.2\% of all patients), pancreatic lipomatosis (14.3\% of all patients) and aortic sclerosis (13.9\% of all patients). Based on glucocorticoid and disease-modifying antirheumatic drug use, we identified cases where immuno-modulatory medication was escalated; there was an association between therapy escalation and the findings of hepatomegaly and pleural effusion (as tested via Fisher's exact test). In patients with several examinations during the defined time span $(n=318)$, we found ultrasound findings to change, especially findings of hepatomegaly, pleural effusion and splenomegaly. When justifying decisions regarding the further treatment of a patient in the discharge letter, abdominal ultrasound results were rarely discussed. Abdominal ultrasound rarely yielded disease-specific or treatmentchanging results.
\end{abstract}

Keywords: systemic autoimmune rheumatic disease; connective tissue disease; abdominal ultrasound; imaging

\section{Introduction}

The abdominal ultrasound allows for a relatively quick and safe examination of the abdominal organs. It can also be administered bedside. Systemic autoimmune rheumatic diseases (SARD) are systemic rheumatologic diseases that can affect many abdominal organs. Therefore, SARD patients are often screened for serositis and abdominal organ involvement via ultrasound. However, there are little data on the prevalence and spectrum of sonographic findings in those patients. Most studies have focused on systemic lupus erythematosus (SLE) and its involvement in specific organs. Previously published research highlights liver and spleen enlargement in childhood-onset SLE [1], prevalence of liver haemangiomas [2], cholecystitis [3], intestinal vasculitis [4] and pancreatitis in SLE [5]. Other SARD entities are less well studied. To date, there are no society guidelines or recommendations regarding the use of abdominal ultrasound in SARD patients. In daily clinical practice, common indications include screening for abdominal organ involvement, monitoring serositis (especially under therapy), examining symptoms, such as abdominal 
pain or nausea, and correlating pathological laboratory parameters. Moreover, abdominal ultrasound can detect lymphadenopathy as a sign of lymphoma, which is associated with some forms of SARD [6].

In this study, we retrospectively analysed the prevalence and spectrum of abdominal ultrasound findings in different SARD entities. Our hospital is a tertiary referral centre for rheumatology patients, both aiding in a first diagnosis and in adjusting therapy regimens in the course of the disease. Abdominal ultrasound is performed liberally at all stages of SARD diseases. As a referral centre, we often decide whether a patient's immunosuppressive medication should be adjusted. In this study, we analyse whether certain abdominal ultrasound findings were more frequent in patients who were put on a higher level of immunosuppressive therapy during their stay, indicating an active state of disease. Lastly, we examine whether abdominal ultrasound findings impacted the therapeutic decisionmaking process.

\section{Materials and Methods}

\subsection{Patients and Data Collection}

We conducted a retrospective cohort study including all patients fulfilling the following criteria:

- Inpatient stay in our tertiary referral centre (Immanuel Krankenhaus Berlin Buch) between 1 January 2006 and 31 December 2015

- Diagnosis of a SARD: SLE, primary or secondary Sjögren's syndrome (SS), systemic sclerosis (SSc; diffuse, limited, overlap with myositis), polymyositis (PM), dermatomyositis (DM), anti-synthetase syndrome, undifferentiated connective tissue disease (UCTD) or mixed connective tissue disease (MCTD).

- Abdominal ultrasound examination From their medical records, we collected the following data:

- Patient characteristics including sex, age, disease duration, former organ manifestations and SARD entity.

- Some patients had a diagnosis of rheumatoid arthritis (RA), secondary SS or an antiphospholipid syndrome (APLS) in addition to their main SARD diagnosis. Their percentage is given in Table 1, labelled as "additional [diagnosis of]".

- Results from abdominal ultrasound examination

- The treating clinician's interpretation of the ultrasound examination results and their relevance to the therapy strategy as described in the hospital discharge letter

- Immunosuppressive therapy at the time of admission and discharge from the clinic that involved glucocorticoid dose (calculated as prednisolone equivalent), type and dose of disease-modifying anti-rheumatic drugs (DMARDs).

Table 1. Patient characteristics.

\begin{tabular}{|c|c|c|c|c|c|c|c|c|c|c|c|c|}
\hline & \multirow[t]{2}{*}{$\begin{array}{c}\text { All } \\
\text { Patients }\end{array}$} & \multirow[t]{2}{*}{ SLE } & \multicolumn{2}{|c|}{ SS } & \multicolumn{3}{|c|}{$\mathrm{SSc}$} & \multicolumn{3}{|c|}{ Myositis } & \multirow[t]{2}{*}{ UCTD } & \multirow[t]{2}{*}{ MCTD } \\
\hline & & & Prim. & Sec. & Diffuse & Lim. & $\begin{array}{l}\text { with } \\
\text { Myos. }\end{array}$ & $\mathbf{P M}$ & DM & $\begin{array}{c}\text { Anti- } \\
\text { Synthetase }\end{array}$ & & \\
\hline $\begin{array}{l}\text { Number of } \\
\text { patients }\end{array}$ & 1092 & 338 & 335 & 250 & 150 & 197 & 34 & 40 & 43 & 37 & 122 & 149 \\
\hline $\begin{array}{l}\text { Percentage of } \\
\text { cohort }(\%)\end{array}$ & 100 & 19.9 & 19.8 & 14.8 & 8.9 & 11.6 & 2.0 & 2.4 & 2.5 & 2.2 & 7.2 & 8.8 \\
\hline add. RA (\%) & 15.0 & 5.2 & 2.8 & 82.6 & - & 4.0 & 5.9 & - & - & - & 2.0 & 1.2 \\
\hline add. APLS (\%) & 5.6 & 23.2 & 0.8 & 0.6 & 1.3 & 0.8 & - & - & - & 6.3 & 4.0 & 6.9 \\
\hline add. Sjögren (\%) & 11.8 & 33.0 & - & - & 15.4 & 18.4 & 17.7 & 4.2 & - & 31.3 & 5.1 & 18.4 \\
\hline New diagnosis (\%) & 33.2 & 17.5 & 40.9 & 20.4 & 30.8 & 40.0 & 53.9 & 41.7 & 42.4 & 31.3 & 51.5 & 33.3 \\
\hline
\end{tabular}


Table 1. Cont.

\begin{tabular}{|c|c|c|c|c|c|c|c|c|c|c|c|c|}
\hline & \multirow[t]{2}{*}{$\begin{array}{c}\text { All } \\
\text { Patients }\end{array}$} & \multirow[t]{2}{*}{ SLE } & \multicolumn{2}{|c|}{ ss } & \multicolumn{3}{|c|}{$\mathrm{SSc}$} & \multicolumn{3}{|c|}{ Myositis } & \multirow[t]{2}{*}{ UCTD } & \multirow[t]{2}{*}{ MCTD } \\
\hline & & & Prim. & Sec. & Diffuse & Lim. & $\begin{array}{l}\text { with } \\
\text { Myos. }\end{array}$ & PM & DM & $\begin{array}{c}\text { Anti- } \\
\text { Synthetase }\end{array}$ & & \\
\hline Women (\%) & 87.6 & 88.7 & 93.7 & 93.4 & 80.8 & 92.8 & 64.7 & 45.8 & 72.7 & 87.5 & 81.8 & 82.8 \\
\hline Men (\%) & 12.5 & 11.3 & 6.4 & 6.6 & 19.2 & 7.2 & 35.3 & 54.2 & 27.3 & 12.5 & 18.2 & 17.2 \\
\hline \multicolumn{13}{|c|}{ Disease duration in years } \\
\hline mean & 6.5 & 9.8 & 5.0 & 11.9 & 3.7 & 4.1 & 1.6 & 4.1 & 4.5 & 6.4 & 2.2 & 5.4 \\
\hline $\min$. & 0.0 & 0.0 & 0.0 & 0.0 & 0.0 & 0.0 & 0.0 & 0.0 & 0.0 & 0.0 & 0.0 & 0.0 \\
\hline max. & 52.8 & 46.3 & 52.8 & 52.6 & 33.2 & 36.8 & 10.0 & 17.0 & 31.2 & 25.7 & 19.9 & 33.3 \\
\hline SD & 9.2 & 9.9 & 8.0 & 12.5 & 5.3 & 6.7 & 3.1 & 5.5 & 8.1 & 8.5 & 4.8 & 7.3 \\
\hline \multicolumn{13}{|l|}{ Age in years } \\
\hline mean & 55.2 & 45.2 & 58.4 & 61.8 & 60.4 & 60.3 & 53.5 & 59.1 & 55.3 & 55.3 & 54.4 & 43.7 \\
\hline $\min$. & 17 & 18 & 18 & 22 & 32 & 28 & 17 & 22 & 20 & 23 & 19 & 20 \\
\hline max. & 90 & 79 & 86 & 87 & 84 & 90 & 79 & 82 & 84 & 73 & 83 & 79 \\
\hline SD & 15.8 & 16.2 & 15.2 & 12.4 & 12.1 & 12.7 & 17.6 & 14.6 & 17.2 & 12.8 & 14.6 & 15.1 \\
\hline \multicolumn{13}{|l|}{ BMI $[\mathrm{kg} / \mathrm{m}]$} \\
\hline mean & 25.8 & 25.1 & 26.2 & 26.3 & 25.4 & 26.4 & 24.3 & 24.7 & 24.8 & 26.0 & 26.4 & 25.1 \\
\hline $\min$. & 14.4 & 16.1 & 15.6 & 17.1 & 15.0 & 17.9 & 15.3 & 14.9 & 14.4 & 18.6 & 14.7 & 16.8 \\
\hline $\max$. & 54.1 & 44.6 & 49.2 & 41.8 & 40.1 & 39.8 & 34.7 & 36.2 & 34.1 & 40.2 & 48.3 & 54.1 \\
\hline \multirow[t]{2}{*}{ SD } & 5.4 & 4.9 & 6.0 & 5.2 & 5.2 & 5.4 & 5.9 & 5.4 & 4.6 & 5.2 & 5.6 & 5.6 \\
\hline & & $\begin{array}{l}\text { Abbr } \\
\text { Myo } \\
\text { MCT } \\
\text { arthr } \\
(\mathrm{n}=\end{array}$ & $\begin{array}{l}\text { ons: } \\
\text { yositi } \\
\text { ixed } \\
\text { nin.: }\end{array}$ & $\begin{array}{l}\text { syst } \\
\text { M: p } \\
\text { nectiv } \\
\text { imur }\end{array}$ & $\begin{array}{l}\text { lupus } \\
\text { yyositis, } \\
\text { sue dis } \\
\text { lax.: ma }\end{array}$ & $\begin{array}{l}\text { ythe } \\
\text { m: } \\
\text { se, a } \\
\text { mur }\end{array}$ & $\begin{array}{l}\text { 1s, SS: } \\
\text { tomyo } \\
\text { ddition } \\
\text { standa }\end{array}$ & $\begin{array}{l}\text { ''s sy } \\
\text { JCTD } \\
\text { LS: a } \\
\text { viatic }\end{array}$ & $\begin{array}{l}\text { me, Ss } \\
\text { differe } \\
\text { nosph } \\
\text { MI: bo }\end{array}$ & $\begin{array}{l}\text { ystemic scl } \\
\text { ated conne } \\
\text { id syndron } \\
\text { mass index }\end{array}$ & $\begin{array}{l}\text { rosis, lin } \\
\text { ive tiss } \\
\text { " RA: rh } \\
\text { "_" sigr }\end{array}$ & $\begin{array}{l}\text { limited } \\
\text { disease } \\
\text { umatoid } \\
\text { fies } 0.0 \%\end{array}$ \\
\hline
\end{tabular}

Data were collected in accordance to the Declaration of Helsinki. The ethics board of the Berlin Board of Physicians (Berliner Ärztekammer) approved the study (Eth-23-16).

\subsection{Abdominal Ultrasound Parameters}

Table 2 refers to the complete list of ultrasound parameters assessed. Examinations were performed by either of two rheumatologists, both are board certified in conducting abdominal ultrasound. Examinations were performed on a Esaote MyLab Twice machine with a 1-6 MHz convex probe.

Table 2. Prevalence of abdominal ultrasound findings in systemic autoimmune rheumatic diseases.

\begin{tabular}{|c|c|c|c|c|c|c|c|c|c|c|c|c|}
\hline & \multirow[t]{2}{*}{$\begin{array}{c}\text { All } \\
\text { Patients }\end{array}$} & \multirow[t]{2}{*}{ SLE } & \multicolumn{2}{|c|}{ SS } & \multicolumn{3}{|c|}{ SSc } & \multicolumn{3}{|c|}{ Myositis } & \multirow[t]{2}{*}{ UCTD } & \multirow[t]{2}{*}{ MCTD } \\
\hline & & & Prim. & Sec. & Diffuse & Lim. & $\begin{array}{l}\text { with } \\
\text { Myos. }\end{array}$ & PM & DM & $\begin{array}{c}\text { Anti- } \\
\text { Synthetase }\end{array}$ & & \\
\hline Number of patients & 1092 & 194 & 252 & 167 & 78 & 125 & 17 & 24 & 33 & 16 & 99 & 87 \\
\hline \multirow[t]{2}{*}{ Number of females } & 956 & 172 & 236 & 156 & 63 & 116 & 11 & 11 & 24 & 14 & 81 & 72 \\
\hline & \multicolumn{12}{|c|}{ Frequency of findings (\%) } \\
\hline \multicolumn{13}{|l|}{ Liver } \\
\hline Hepatomegaly & 8.1 & 9.8 & 9.1 & 5.4 & 12.8 & 5.6 & 11.8 & 12.5 & - & 6.3 & 4.0 & 11.5 \\
\hline Fatty liver & 26.8 & 23.7 & 23.8 & 36.5 & 32.1 & 24.8 & 29.4 & 41.7 & 24.2 & 31.3 & 26.3 & 18.4 \\
\hline Cirrhosis & 0.5 & - & 0.4 & 0.6 & - & 3.2 & - & - & - & - & - & - \\
\hline Focal nodular hyperplasia & 0.2 & 0.5 & - & 0.6 & - & - & - & - & - & - & - & - \\
\hline Haemangioma & 2.6 & 2.1 & 3.6 & 1.2 & 1.3 & 1.6 & 5.9 & 4.2 & - & - & 4.0 & 4.6 \\
\hline Abscess & 0.1 & - & - & - & - & - & - & - & - & - & 1.0 & - \\
\hline
\end{tabular}


Table 2. Cont.

\begin{tabular}{|c|c|c|c|c|c|c|c|c|c|c|c|c|}
\hline & \multirow[t]{2}{*}{$\begin{array}{c}\text { All } \\
\text { Patients }\end{array}$} & \multirow[t]{2}{*}{ SLE } & \multicolumn{2}{|c|}{ SS } & \multicolumn{3}{|c|}{ SSc } & \multicolumn{3}{|c|}{ Myositis } & \multirow[t]{2}{*}{ UCTD } & \multirow[t]{2}{*}{ MCTD } \\
\hline & & & Prim. & Sec. & Diffuse & Lim. & $\begin{array}{l}\text { with } \\
\text { Myos. }\end{array}$ & PM & DM & $\begin{array}{c}\text { Anti- } \\
\text { Synthetase }\end{array}$ & & \\
\hline Dilated hepatic veins & 0.8 & 0.5 & 0.8 & 0.6 & 1.3 & 1.6 & - & 4.2 & - & 6.3 & - & - \\
\hline Dilated common hepatic duct & 1.3 & 1.5 & 0.8 & 3.0 & 1.3 & 1.6 & - & - & - & - & - & 1.1 \\
\hline Suspected malignant tumour & 0.5 & - & 0.4 & - & 1.3 & - & - & - & 3.0 & - & 2.0 & - \\
\hline \multicolumn{13}{|l|}{ Gallbladder } \\
\hline Concrements & 8.2 & 6.7 & 10.7 & 7.2 & 10.3 & - & 5.9 & 16.7 & 12.1 & 6.3 & 6.1 & 5.7 \\
\hline Thickening of wall & 0.5 & - & 0.4 & 1.2 & - & - & - & - & - & 6.3 & 2.0 & - \\
\hline Polyp & 1.6 & 2.6 & 1.6 & 2.4 & 1.3 & - & - & 4.2 & - & - & - & 2.3 \\
\hline Status post cholecystectomy & 14.4 & 8.8 & 17.9 & 20.4 & 14.1 & 17.6 & 5.9 & 25.0 & 3.0 & 6.3 & 14.1 & 5.7 \\
\hline \multicolumn{13}{|l|}{ Pancreas } \\
\hline Pancreatic lipomatosis & 14.3 & 10.8 & 11.1 & 25.1 & 15.4 & 12.0 & 23.5 & 25.0 & 15.2 & 37.5 & 14.1 & 3.4 \\
\hline Inhomogeneous parenchyma & 1.9 & 2.6 & 1.6 & - & - & 0.8 & - & 4.2 & 6.1 & 6.3 & 3.0 & 4.6 \\
\hline Pancreatitis & 0.2 & 0.5 & - & 0.6 & - & - & - & - & - & - & - & - \\
\hline Cyst & 0.2 & 0.5 & - & 0.6 & - & - & - & - & - & - & - & - \\
\hline Lesion/tumour & 0.5 & - & 0.4 & - & 1.3 & 1.6 & - & 4.2 & - & - & - & - \\
\hline \multicolumn{13}{|l|}{ Kidneys } \\
\hline Altered echogenicity & 4.7 & 5.7 & 6.0 & 4.2 & 7.7 & 4.8 & - & 8.3 & 6.1 & - & - & 2.3 \\
\hline Hydronephrosis & 2.2 & 1.5 & 2.4 & 1.2 & 6.4 & 3.2 & - & 8.3 & 3.0 & - & - & 1.1 \\
\hline Cyst & 10.3 & 9.3 & 10.7 & 12.6 & 15.4 & 9.6 & 5.9 & 4.2 & 15.2 & 25.0 & 8.1 & 4.6 \\
\hline Concrements & 2.5 & 2.1 & 2.8 & 3.0 & 3.8 & 2.4 & 5.9 & 4.2 & - & - & 1.0 & 2.3 \\
\hline Lesion/tumour & 0.6 & 0.5 & 0.8 & - & 3.8 & - & - & - & 3.0 & - & - & - \\
\hline \multicolumn{13}{|l|}{ Spleen } \\
\hline Splenomegaly & 15.2 & 24.7 & 12.7 & 9.6 & 16.7 & 13.6 & 17.6 & 25.0 & 9.1 & 12.5 & 10.1 & 18.4 \\
\hline Altered echogenicity & 0.9 & 2.1 & 0.4 & 1.2 & - & 0.8 & - & - & - & - & - & 2.3 \\
\hline Calcification & 1.8 & 4.1 & 0.8 & 1.8 & 1.3 & 3.2 & - & - & - & - & 1.0 & 1.1 \\
\hline Status post splenectomy & 0.4 & 1.0 & - & 0.6 & - & - & - & - & - & - & - & 1.1 \\
\hline \multicolumn{13}{|l|}{ Aorta } \\
\hline Sclerosis & 13.9 & 11.3 & 11.9 & 23.4 & 19.2 & 13.6 & 17.6 & 12.5 & 15.2 & 18.8 & 10.1 & 5.7 \\
\hline Aortitis & 0.1 & - & 0.4 & - & - & - & - & - & - & - & - & - \\
\hline Aneurysm & 0.6 & 1.5 & - & 0.6 & 1.3 & 0.8 & - & - & 3.0 & - & - & - \\
\hline \multicolumn{13}{|l|}{ Genito-urinary } \\
\hline Abnormal bladder wall & 1.3 & 0.5 & 2.0 & - & 2.6 & - & - & 4.2 & 3.0 & - & 3.0 & 1.1 \\
\hline \multicolumn{13}{|l|}{ Female patients only } \\
\hline Abnormal uterus & 4.5 & 7.0 & 3.0 & 3.8 & 4.8 & 5.2 & - & - & 4.2 & 7.1 & 4.9 & 4.2 \\
\hline Status post hysterectomy & 11.3 & 8.1 & 13.1 & 15.4 & 7.9 & 12.9 & - & 9.1 & 12.5 & 14.3 & 11.1 & 5.6 \\
\hline \multicolumn{13}{|l|}{ Male patients only } \\
\hline Prostatic hyperplasia & 8.8 & 4.5 & 31.3 & - & 20.0 & - & - & - & 11.1 & - & 11.1 & - \\
\hline Prostatic calcification & 5.9 & 4.5 & - & - & 13.3 & - & 16.7 & 15.4 & - & - & 5.6 & 6.7 \\
\hline \multicolumn{13}{|l|}{ Other findings } \\
\hline Pleural effusion & 7.8 & 14.4 & 5.6 & 4.2 & 10.3 & 7.2 & 5.9 & 4.2 & 3.0 & 6.3 & 7.1 & 9.2 \\
\hline Pericardial effusion ${ }^{1}$ & 0.6 & 2.1 & 0.4 & - & 1.3 & - & - & - & - & - & 1.0 & - \\
\hline Ascites & 2.2 & 4.1 & 0.4 & 0.6 & 6.4 & 3.2 & - & 4.2 & - & 6.3 & 1.0 & 2.3 \\
\hline Colitis & 2.4 & 1.5 & 2.4 & 2.4 & 2.6 & 3.2 & - & 4.2 & 6.1 & - & 2.0 & 2.3 \\
\hline Lymphadenopathy & 0.2 & - & - & - & 1.3 & 0.8 & - & - & - & - & - & - \\
\hline Hernia & 0.6 & - & 1.2 & 1.2 & - & 0.8 & - & - & - & - & 1.0 & - \\
\hline
\end{tabular}

Abbreviations: SLE: systemic lupus erythematosus, PM: polymyositis, DM: dermatomyositis, UCTD: undifferentiated connective tissue disease, MCTD: mixed connective tissue disease. " - "signifies $0.0 \%(n=0) .{ }^{1}$ Pericardial effusions were not looked for routinely in abdominal ultrasound, but were occasionally seen in subxiphoidal view. These cases were followed up via echocardiography.

\subsection{Escalation of Therapy}

Therapy was labelled as escalated, de-escalated or unchanged based on changes in glucocorticoid and DMARD treatment between admission and discharge. We defined 
escalation of therapy as increase of glucocorticoid and/or DMARD doses. Escalation was also assumed when DMARDs were switched with the intention of reducing disease activity (as described in the discharge letter). De-escalation was defined as reduced glucocorticoid and/or DMARD doses and/or DMARD switches intended to reduce the level of immunosuppression.

We also noted when therapy was changed (or remained unchanged) upon factors other than the activity of a patient's SARD. Such factors included active infections, planned surgery and pregnancies. In patients with secondary SS, we noted if changes in therapy were targeting concomitant rheumatic diseases (see Table 1).

\subsection{Relevance of Ultrasound Results for Therapeutic Decision Making}

We analysed the discharge summary section in the discharge letter of all cases. We noted whether the treating physician discussed abdominal ultrasound results when explaining the reasoning behind his therapeutic decisions.

\subsection{Statistics}

Patient characteristics are described as means corresponding to 95\% confidence intervals (quantitative variables) and as frequencies (qualitative variables).

The frequency of ultrasound findings was analysed in the whole cohort and within each SARD entity.

We compared the occurrence of sonographic findings between cases with and without escalation of therapy via Fisher's exact test; $p<0.05$ was considered significant. Cases without escalated therapy included those with de-escalated and with unchanged therapy. Cases in which therapeutic decisions were based on factors other than the SARD were excluded. If an ultrasound examination missed the description of a particular finding, the case was excluded from the analysis for said finding.

Patients with several stays during the time span were analysed as follows:

- $\quad$ Patient characteristics were derived from the first visit.

- To calculate the frequency of ultrasound findings, we determined if they were reported in any examination.

- To test which findings were associated with escalation of therapy, we analysed all eligible cases related to a patient (see above).

To describe the change of findings over time, we selected cases of patients with repetitive examinations. For each finding, we calculated the number and proportion of patients who

- Showed the finding at first examination.

- Showed the finding at any examination.

- Developed the finding between two examinations.

- Showed resolution of a finding between two examinations.

\section{Results}

\subsection{Patient Characteristics}

We included 1092 patients with a total of 1695 abdominal ultrasound examinations. A total of 956 patients (87.6\%) were female; the mean age was 55.2 years (min. 17 years, max. 90 years, SD 15.8). Patient characteristics are displayed in Table 1.

\subsection{Frequency of Abdominal Ultrasound Findings in Different Systemic Autoimmune Rheumatic Diseases}

Table 2 shows the frequency of each abdominal ultrasound finding in the overall cohort and per SARD entity. The most frequent findings were hepatic steatosis (26.8\%), splenomegaly (15.2\%), pancreatic lipomatosis (14.3\%) and hepatomegaly (8.1\%). Except for MCTD, aortic sclerosis was observed in more than $10 \%$ of patients in all SARD entities. 
Pleural effusions (PEs) were most frequent in SLE (14.4\%), diffuse SSc $(10.3 \%)$ and MCTD (9.2\%). Ascites was rarely observed (2.2\% of all patients) with no higher occurrence in any SARD entity.

\subsection{Change of Abdominal Ultrasound Findings over Time}

A total of 318 inpatients received an abdominal ultrasound more than once during the duration of analysis. Table 3 displays the changes of ultrasound results over time in-between examinations. We most often observed development of splenomegaly in $8.8 \%$ of patients and of hepatomegaly in $7.2 \%$ of patients. Renal parenchymal alterations $(6.0 \%)$, PE (5.6\%) and signs of colitis (4.1\%) were also developed between repetitive ultrasound examinations. Hepato- and splenomegaly and PE were also resolved between examinations.

Table 3. Changes over time in 318 patients with repetitive abdominal ultrasound examinations.

\begin{tabular}{|c|c|c|c|c|c|c|}
\hline & $\begin{array}{l}\text { Patients with } \\
\text { Finding in First } \\
\text { Examination (n) }\end{array}$ & $\begin{array}{l}\text { Patients with } \\
\text { Finding in Any } \\
\text { Examination (n) }\end{array}$ & \multicolumn{2}{|c|}{$\begin{array}{l}\text { Patients with Development of } \\
\text { Finding Between Two Examinations }\end{array}$} & \multicolumn{2}{|c|}{$\begin{array}{c}\text { Patients with Resolution of } \\
\text { Finding Between Two } \\
\text { Examinations }\end{array}$} \\
\hline \multicolumn{7}{|c|}{ Serositis } \\
\hline Pericardial effusion & 1 & 4 & $\mathrm{n}=3$ & $0.9 \%$ & $\mathrm{n}=1$ & $0.3 \%$ \\
\hline Pleural effusion & 17 & 35 & $\mathrm{n}=18$ & $5.6 \%$ & $\mathrm{n}=23$ & $7.2 \%$ \\
\hline \multirow{2}{*}{\multicolumn{7}{|c|}{$\begin{array}{l}16 \\
\text { Organomegaly }\end{array}$}} \\
\hline & & & & & & \\
\hline Hepatomegaly & 22 & 45 & $\mathrm{n}=23$ & $7.2 \%$ & $\mathrm{n}=30$ & $9.4 \%$ \\
\hline Splenomegaly & 40 & 68 & $\mathrm{n}=28$ & $8.8 \%$ & $\mathrm{n}=37$ & $11.6 \%$ \\
\hline \multicolumn{7}{|c|}{ Parenchymal alterations } \\
\hline Altered renal echogenicity & 5 & 24 & $n=19$ & $6.0 \%$ & $\mathrm{n}=12$ & $3.8 \%$ \\
\hline Altered splenic echogenicity & 4 & 7 & $\mathrm{n}=3$ & $0.9 \%$ & $\mathrm{n}=4$ & $1.3 \%$ \\
\hline Inhomogeneous pancreatic parenchyma & 2 & 11 & $\mathrm{n}=9$ & $2.8 \%$ & $\begin{array}{l}11-4 \\
n=7\end{array}$ & $2.2 \%$ \\
\hline \multicolumn{7}{|c|}{ Inflammatory conditions } \\
\hline Pancreatitis & 0 & & $\mathrm{n}=2$ & $0.6 \%$ & $\mathrm{n}=1$ & $0.3 \%$ \\
\hline Aortitis & 1 & 1 & $\mathrm{n}=0$ & $0.0 \%$ & $\mathrm{n}=0$ & $0.0 \%$ \\
\hline \multirow{2}{*}{\multicolumn{7}{|c|}{$\begin{array}{l}17 \\
\text { Other findings }\end{array}$}} \\
\hline & & & & & & \\
\hline $\begin{array}{l}\text { Aortic aneurysm } \\
\text { Liver cirrhosis }\end{array}$ & $\begin{array}{l}0 \\
1\end{array}$ & $\frac{1}{3}$ & $\begin{array}{l}\mathrm{n}=1 \\
\mathrm{n}=2\end{array}$ & $\begin{array}{l}0.3 \% \\
0.6 \%\end{array}$ & $\begin{array}{l}\mathrm{n}=0 \\
\mathrm{n}=1\end{array}$ & $\begin{array}{l}0.0 \% \\
0.3 \%\end{array}$ \\
\hline
\end{tabular}

\subsection{Frequency of Findings in Cases with Escalation Versus without Escalation of Therapy}

We excluded 268 cases where therapy decisions were not based on SARD activity. Of the remaining 1360 cases, therapy was either escalated or unchanged in 680 cases or de-escalated in 680 cases.

Table 4 compares the frequency of selected ultrasound findings between cases with and without escalated therapy. In cases with escalation of therapy, PE was more frequent than in cases without $(7.8 \%$ versus $3.7 \%, p<0.001)$. Likewise, hepatomegaly was more frequent in cases with escalation of therapy than in those without $(7.7 \%$ versus $4.9 \%, p=0.04)$. The frequency of all other findings mentioned in Table 4 did not differ significantly between cases with and without escalation of therapy.

\subsection{Relevance of Abdominal Ultrasound Findings Affecting Clinical Decision Making}

Rheumatologists seldom discussed abdominal ultrasound findings when explaining the rationale for their treatment regimen. Out of all 1695 ultrasound examinations, only $30(1.5 \%)$ were explicitly mentioned in the decision-making process and documented in the discharge letter. Therapy remained unchanged or could be de-escalated in seven cases based on an unremarkable abdominal ultrasound. In 14 cases, there was pleural effusion, prompting escalation of therapy in eleven cases. Normal abdominal organ status was ensured in three cases before starting a new DMARD therapy and in one case with ongoing cyclophosphamide pulse therapy. One patient was followed up for known aortitis. In five cases, abdominal ultrasound unveiled relevant non-rheumatological conditions: Liver abscess, hepatic metastases of a previously unknown colorectal carcinoma, an inhomogeneous uterus with unilateral hydronephrosis and in two cases cirrhosis of the liver with derailed liver function on laboratory results. 
Table 4. Frequency of abdominal ultrasound findings in cases with versus without escalation of therapy.

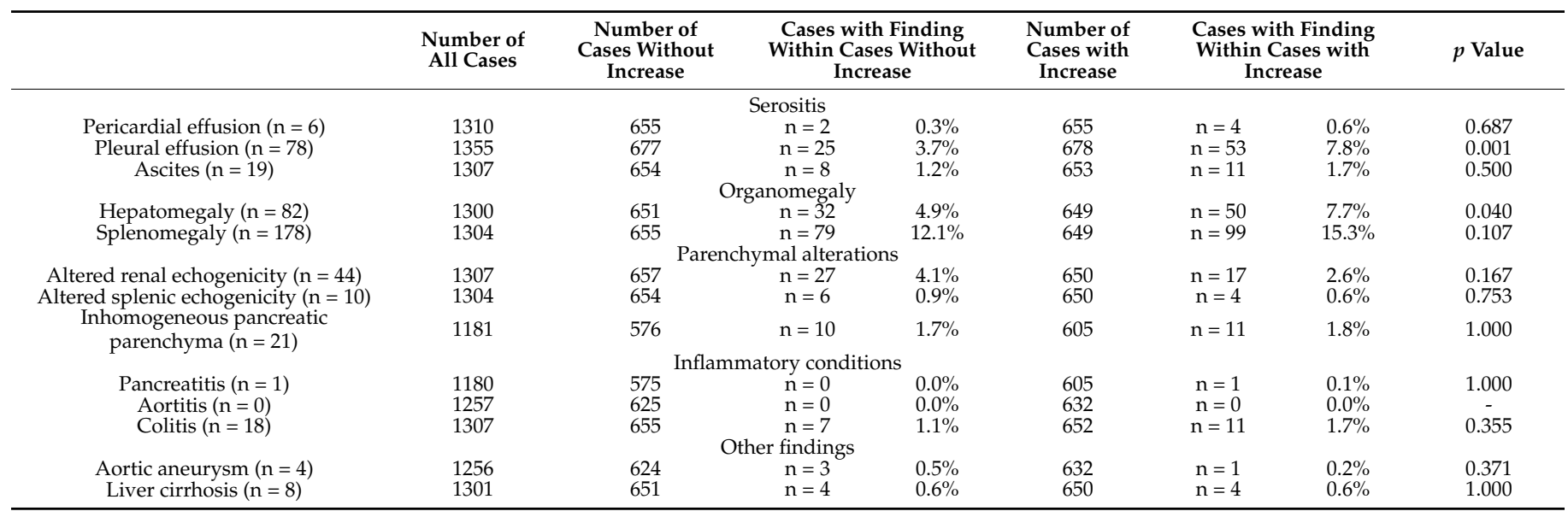

\section{Discussion}

The aim of our study was to investigate the prevalence, clinical significance and changes in the findings observed in routine abdominal ultrasound in a large clinical cohort of SARD patients. To the best of our knowledge, this is the first study evaluating abdominal ultrasound findings in SARD patients systematically. There are only limited data available on the results of abdominal ultrasound examination in patients with SARD. Most frequent findings observed in all SARD entities were hepatic steatosis ( $26.8 \%$ of all patients), pancreatic lipomatosis ( $14.3 \%$ of all patients), aortic sclerosis ( $13.9 \%$ of all patients) and hepato- and splenomegaly ( $8.1 \%$ and $15.2 \%$ of all patients, respectively). Hepatic steatosis is frequently observed in SLE [7,8] and associated with glucocorticoid use [7,9]. A cohort study on 607 patients with RA, SLE, SS, SSc, PM, DM and MCTD described hepatic steatosis as a possible cause for elevated liver enzymes [10]. Pancreatic lipomatosis has not yet been studied in SARD patients, but it seems to be related to hepatic steatosis [11,12]. Pancreatic lipomatosis is also associated with insulin resistance and diabetes mellitus [13] and with metabolic syndrome [14,15]; the latter condition has been observed to occur frequently in SLE [16,17], RA [18] and PM [19]. Patients with SARD diseases carry a high cardiovascular risk $[20,21]$. Several recommendations highlight the importance of screening for cardiovascular health in patients with rheumatic diseases [22-25]. Hence, the finding of hepatic steatosis or pancreatic lipomatosis might prompt the rheumatologist to screen for further cardiovascular risk factors.

Splenomegaly is a common condition in SLE [26] and may coexist with hepatomegaly [26]. The cause for splenomegaly in SLE is unknown. In an autopsy study on SLE patients, periarterial fibrosis of the spleen was a frequent finding [27] and has been proposed as a possible cause for splenomegaly [26]. To date, there are little data on the relationship between the enlargement of the spleen or liver and disease activity in SARD patients. A study by Guariento et al. examined sonographic measurements of the liver and spleen in 30 SLE patients and 30 healthy controls and observed posterior cranio-caudal measurements of the right hepatic lobe to be significantly higher in SLE patients and correlated with higher disease activity scores [1]. All other hepatic and splenic dimensions did not differ significantly between SLE patients and controls; although, a long disease duration in SLE was found to correlate with spleen atrophy [1].

In our study, we observed a correlation of hepatomegaly and the need for escalating immunosuppressive therapy. Our data are thus in line with data reported by Guariento [1] that hepatomegaly might be an expression of disease activity not only in SLE but also in other SARD entities. The idea of hepatomegaly being a dynamic state is also supported by our observation that it sometimes resolved in intermediate examinations. 
Out of all findings in abdominal ultrasound, pleural effusions (PEs) are most extensively studied as markers for disease activity. In SLE patients, they are associated with high disease activity scores [28] and are part of the American College of Rheumatology Classification Criteria [29]. In our cohort, PEs were frequently observed in cases with escalation of therapy. They were also the findings which were often explicitly discussed in the hospital discharge letters. Of all abdominal ultrasound parameters, we suggest that PE is most likely to indicate active disease state.

All other findings did not show an association to escalation of therapy. Findings that might require timely intervention, such as dilation of the common hepatic duct or of liver veins, hydronephrosis, ascites or cholecystitis, were rare and seen in 0.5 to $2.2 \%$ of all patients.

Abdominal lymphadenopathy was only observed in 2 out of 1092 examinations (0.2\%). Abdominal ultrasound is often regarded as a screening tool for lymphoma development in SARD patients. Non-Hodgkin-Lymphoma is supposed to occur more frequently in patients with SLE, RA and primary SS [6]. In SLE, diffuse large cell B-cell lymphoma and marginal cell lymphoma seem to be the most prevalent types of lymphoma [30]. In primary SS, the most prevalent lymphomas are diffuse large cell B-cell lymphoma, follicular lymphoma [31] and parotid gland marginal zone lymphoma [30,32]. These lymphomas can manifest in abdominal lymph nodes (follicular and diffuse large cell lymphoma) and in the spleen or gastric or duodenal mucosa. However, there are inconclusive studies on the sensitivity of ultrasound in lymphoma detection. When compared to computer tomography, one study found ultrasound to be an effective screening method [33]. Another study reported that in ultrasound, both the existence and extent of lymphoma were underestimated [34]. Both studies were published in 1980 and 1983, respectively, and therefore may not reflect the possibilities of modern ultrasound devices. In addition, it is questionable whether there is an advantage in survival when lymphomas are detected in a routine examination versus when being symptomatic. This question has yet to be answered in future studies, and retrospective studies were inconclusive [35]. In summary, it is unclear whether abdominal ultrasound is a sufficiently sensitive method for lymphoma detection. Furthermore, screening asymptomatic patients to catch very early stages has not been proven to result in better outcomes.

\section{Study Limitations}

It is important to note that ultrasound examinations used in this study were performed in a clinical setting; a common intention was to screen patients who were either newly diagnosed or had not been assessed by a rheumatologist in a while but also to correlate unspecific abdominal symptoms or altered laboratory parameters. The exact reason for the examinations being performed was not always evident from the medical records. While abdominal ultrasound examinations are done regularly during examinations in patients with SARD, we did not perform them at every visit. Therefore, when comparing our findings to previously published studies, there may have been a different approach as to whether and how patients were selected for abdominal ultrasound examinations.

Ultrasound was performed by either of two experienced physicians. As we analysed retrospective data that were collected in a clinical setting, examination results were not validated by a second sonographer. Changes of findings between visits might partially be attributable to variability between examiners, although abdominal ultrasound has been shown to be reliable and reproducible [36]. Patients with secondary Sjögren's syndrome had different underlying diseases, mostly rheumatoid arthritis (82.1\%). It should be noted that in secondary Sjögren's syndrome, we do not know if abdominal ultrasound findings are influenced by the secondary SS, the underlying disease or both. Furthermore, we did we not analyse the relation between ultrasound findings and established disease activity scores, but rather assumed that changes in anti-inflammatory medication reflected the current disease activity. This parameter was chosen for being available for each patient visit and across all SARD entities. We had to rely on the hospital discharge letter while studying 
the impact of examinations on therapeutic decision making. We cannot exclude that these results have been discussed more extensively elsewhere, for instance verbally between examining and treating physicians. Lastly, our cohort was hospitalized in a referral centre. The spectrum of findings might be different in an outpatient setting.

\section{Conclusions}

Our study illustrates the prevalence and spectrum of abdominal ultrasound results in a large cohort of SARD patients, both at the time of first diagnosis and during follow-up visits. In cases where immunosuppressive therapy had to be escalated, PE and hepatomegaly were more frequent than in cases with unchanged or de-escalated therapy. In accordance with previously published studies, we suggest that these findings indicate disease activity. They were also found to change in between follow-up examinations. However, ultrasound results were seldom pivotal when deciding upon changes in therapy. Abdominal ultrasound also rarely revealed findings unspecific for SARD that required immediate intervention. In conclusion, we suggest that abdominal ultrasound does not need to be performed routinely in asymptomatic SARD patients. Likewise, there is not enough evidence for ultrasound being a sensitive method for detecting the development of lymphoma. We rather see its place in evaluating symptomatic patients, patients with known abdominal conditions or those with laboratory parameter alterations.

Author Contributions: All authors have contributed substantially to this paper. Conceptualization, V.S.S.; methodology, K.W.; data curation, K.W.; resources; A.K. and W.A.S.; writing-original draft preparation, K.W.; writing-review and editing, W.A.S., A.K. and V.S.S.; supervision, W.A.S., A.K. and V.S.S. All authors have read and agreed to the published version of the manuscript.

Funding: This research received no external funding.

Institutional Review Board Statement: Data were collected in accordance to the Declaration of Helsinki. The ethics board of the Berlin Board of Physicians (Berliner Ärztekammer) approved the study (Eth-23-16).

Informed Consent Statement: Patient consent could not be obtained due to the retrospective nature of this study.

Data Availability Statement: The authors confirm that all data of this study are available within the article.

Acknowledgments: We thank Aaron Juche at Immanuel Krankenhaus Berlin who conducted many of the ultrasound examinations that were analysed for this paper.

Conflicts of Interest: The authors declare no conflict of interest.

\section{References}

1. Guariento, A.; Silva, M.F.C.; Tassetano, P.S.; Rocha, S.M.S.; Campos, L.M.; Valente, M.; Silva, C.A. Biometria do fígado e do baço em pacientes com lúpus eritematoso sistêmico de início pediátrico. Rev. Bras. Reum. 2015, 55, 346-351. [CrossRef]

2. Berzigotti, A. Liver hemangioma and vascular liver diseases in patients with systemic lupus erythematosus. World J. Gastroenterol. 2011, 17, 4503-4508. [CrossRef]

3. Kamimura, T.; Mimori, A.; Takeda, A.; Masuyama, J.; Yoshio, T.; Okazaki, H.; Kano, S.; Minota, S. Acute acalculous cholecystitis in systemic lupus erythematosus: A case report and review of the literature. Lupus 1998, 7, 361-363. [CrossRef]

4. Shiohira, Y.; Uehara, H.; Miyazato, F.; Matsumoto, H. Vasculitis-related acute abdomen in systemic lupus erythemato-susultrasound appearances in lupus patients with intra-abdominal vasculitis. Ryumachi 1993, 33, $235-241$.

5. Nesher, G.; Breuer, G.S.; Temprano, K.; Moore, T.L.; Dahan, D.; Baer, A.; Alberton, J.; Izbicki, G.; Hersch, M. Lupus-Associated Pancreatitis. Semin. Arthritis Rheum. 2006, 35, 260-267. [CrossRef] [PubMed]

6. Zintzaras, E.; Voulgarelis, M.; Moutsopoulos, H.M. The Risk of Lymphoma Development in Autoimmune Diseases. Arch. Intern. Med. 2005, 165, 2337-2344. [CrossRef] [PubMed]

7. Matsumoto, T.; Yoshimine, T.; Shimouchi, K.; Shiotu, H.; Kuwabara, N.; Fukuda, Y.; Hoshi, T. The liver in systemic lupus erythematosus: Pathologic analysis of 52 cases and review of Japanese autopsy registry data. Hum. Pathol. 1992, 23, 1151-1158. [CrossRef]

8. Grover, S.; Rastogi, A.; Singh, J.; Rajbongshi, A.; Bihari, C. Spectrum of Histomorphologic Findings in Liver in Patients with SLE: A Review. Hepat. Res. Treat. 2014, 2014, 1-7. [CrossRef] 
9. Hallegua, D.S.; Venuturupalli, S. Chapter 33-Gastrointestinal and Hepatic Manifestations A2. In Dubois' Lupus Erythematosus and Related Syndromes, 18th ed.; Wallace, D., Hahn, B.H., Eds.; W.B. Saunders: Philadelphia, PA, USA, 2013 ; pp. $415-425$.

10. Takahashi, A.; Abe, K.; Yokokawa, J.; Iwadate, H.; Kobayashi, H.; Watanabe, H.; Irisawa, A.; Ohira, H. Clinical features of liver dysfunction in collagen diseases. Hepatol. Res. 2010, 40, 1092-1097. [CrossRef]

11. Della Corte, C.; Mosca, A.; Majo, F.; Lucidi, V.; Panera, N.; Giglioni, E.; Monti, L.; Stronati, L.; Alisi, A.; Nobili, V. Nonalcoholic fatty pancreas disease and Nonalcoholic fatty liver disease: More than ectopic fat. Clin. Endocrinol. 2015, 83, 656-662. [CrossRef]

12. Van Geenen, E.-J.M.; Smits, M.M.; Schreuder, T.C.; van der Peet, D.L.; Bloemena, E.; Mulder, C.J. Nonalcoholic Fatty Liver Disease Is Related to Nonalcoholic Fatty Pancreas Disease. Pancreas 2010, 39, 1185-1190. [CrossRef]

13. Yu, T.-Y.; Wang, C.-Y. Impact of non-alcoholic fatty pancreas disease on glucose metabolism. J. Diabetes Investig. 2017, 8, 735-747. [CrossRef] [PubMed]

14. Tariq, H.; Nayudu, S.; Akella, S.; Glandt, M.; Chilimuri, S. Non-Alcoholic Fatty Pancreatic Disease: A Review of Literature. Gastroenterol. Res. 2016, 9, 87-91. [CrossRef]

15. Singh, R.; Yoon, H.D.; Wu, L.M.; Lu, J.; Plank, L.D.; Petrov, M.S. Ectopic fat accumulation in the pancreas and its clinical relevance: A systematic review, meta-analysis, and meta-regression. Metabolism 2017, 69, 1-13. [CrossRef] [PubMed]

16. Medeiros, M.M.D.C.; De Oliveira, Í.M.X.; Ribeiro, A.T. Prevalence of metabolic syndrome in a cohort of systemic lupus erythematosus patients from Northeastern Brazil: Association with disease activity, nephritis, smoking, and age. Rheumatol. Int. 2015, 36, 117-124. [CrossRef] [PubMed]

17. Parker, B.; Bruce, I. SLE and metabolic syndrome. Lupus 2013, 22, 1259-1266. [CrossRef]

18. Zhang, J.; Fu, L.; Shi, J.; Chen, X.; Li, Y.; Ma, B.; Zhang, Y. The Risk of Metabolic Syndrome in Patients with Rheumatoid Arthritis: A Meta-Analysis of Observational Studies. PLoS ONE 2013, 8, e78151. [CrossRef]

19. Parker, B.; Urowitz, M.B.; Gladman, D.D.; Lunt, M.; Bae, S.-C.; Sanchez-Guerrero, J.; Romero-Diaz, J.; Gordon, C.; Wallace, D.J.; Clarke, A.; et al. Clinical associations of the metabolic syndrome in systemic lupus erythematosus: Data from an international inception cohort. Ann. Rheum. Dis. 2012, 72, 1308-1314. [CrossRef]

20. Alenghat, F.J. The Prevalence of Atherosclerosis in Those with Inflammatory Connective Tissue Disease by Race, Age and Traditional Risk Factors. Sci. Rep. 2016, 6, 20303. [CrossRef]

21. Symmons, D.; Gabriel, S.E. Epidemiology of CVD in rheumatic disease, with a focus on RA and SLE. Nat. Rev. Rheumatol. 2011, 7, 399-408. [CrossRef]

22. Agca, R.; Heslinga, S.C.; Rollefstad, S.; Heslinga, M.; McInnes, I.B.; Peters, M.J.L.; Kvien, T.K.; Dougados, M.; Radner, H.; Atzeni, F.; et al. EULAR recommendations for cardiovascular disease risk management in patients with rheumatoid arthritis and other forms of inflammatory joint disorders: 2015/2016 update. Ann. Rheum. Dis. 2017, 76, 17-28. [CrossRef] [PubMed]

23. Mosca, M.; Tani, C.; Aringer, M.; Bombardieri, S.; Boumpas, D.T.; Brey, R.L.; Cervera, R.; Doria, A.; Jayne, D.; Khamashta, M.; et al European League against Rheumatism recommendations for monitoring patients with systemic lupus erythematosus in clinical practice and in observational studies. Ann. Rheum. Dis. 2009, 69, 1269-1274. [CrossRef]

24. Bertsias, G.; Ioannidis, J.P.; Boletis, J.N.; Bombardieri, S.; Cervera, R.; Dostal, C.; Font, J.; Gilboe, I.M.; Houssiau, F.; Huizinga, T.; et al. EULAR recommendations for the management of systemic lupus erythematosus. Report of a Task Force of the EULAR Standing Committee for International Clinical Studies Including Therapeutics. Ann. Rheum. Dis. 2007, 67, 195-205. [CrossRef]

25. Fiehn, C.; Herzer, P.; Holle, J.; Iking-Konert, C.; Krause, A.; Krüger, K.; Märker-Hermann, E.; Rautenstrauch, J.; Schneider, M. Klug Entscheiden: In der Rheumatologie. Dtsch. Arztebl. Int. 2016, 113, 1154.

26. Karpouzas, G.A. Chapter 34-Hematologic and Lymphoid Abnormalities in SLE A2. In Dubois' Lupus Erythematosus and Related Syndromes, 18th ed.; Wallace, D., Hahn, B.H., Eds.; W.B. Saunders: Philadelphia, PA, USA, 2013; pp. $426-437$.

27. Kaiser, I.H. The specificity of periarterial fibrosis of the spleen in disseminated lupus erythematosus. Am. Hear. J. 1943, $25,137$. [CrossRef]

28. Zhao, J.; Bai, W.; Zhu, P.; Zhang, X.; Liu, S.; Wu, L.; Ma, L.; Bi, L.; Zuo, X.; Sun, L.; et al. Chinese SLE Treatment and Research group (CSTAR) registry VII: Prevalence and clinical significance of serositis in Chinese patients with systemic lupus erythematosus. Lupus 2016, 25, 652-657. [CrossRef]

29. Hochberg, M.C. Updating the American college of rheumatology revised criteria for the classification of systemic lupus erythematosus. Arthritis Care Res. 1997, 40, 1725. [CrossRef] [PubMed]

30. Smedby, K.E.; Vajdic, C.M.; Falster, M.; Engels, E.A.; Martínez-Maza, O.; Turner, J.; Hjalgrim, H.; Vineis, P.; Costantini, A.S.; Bracci, P.M.; et al. Autoimmune disorders and risk of non-Hodgkin lymphoma subtypes: A pooled analysis within the InterLymph Consortium. Blood 2008, 111, 4029-4038. [CrossRef] [PubMed]

31. Baecklund, E.; Sundström, C.; Ekbom, A.; Catrina, A.I.; Biberfeld, P.; Feltelius, N.; Klareskog, L. Lymphoma subtypes in patients with rheumatoid arthritis: Increased proportion of diffuse large B cell lymphoma. Arthritis Care Res. 2003, 48, 1543-1550. [CrossRef]

32. Voulgarelis, M.; Dafni, U.G.; Isenberg, D.A.; Moutsopoulos, H.M. Malignant lymphoma in primary Sjogren's syndrome: A multicenter, retrospective, clinical study by the European Concerted Action on Sjogren's Syndrome. Arthritis Rheum. 1999, 42, 1765-1772. [CrossRef]

33. Beyer, D.; Peters, P.E. Real-time ultrasonography-an efficient screening method for abdominal and pelvic lymphade-nopathy. Lymphology 1980, 13, 142-149. [PubMed] 
34. Neumann, C.H.; Robert, N.J.; Rosenthal, D.; Canellos, G. Clinical Value of Ultrasonography for the Management of Non-Hodgkin Lymphoma Patients as Compared with Abdominal Computed Tomography. J. Comput. Assist. Tomogr. 1983, 7, 666-669. [CrossRef] [PubMed]

35. Cohen, J.B.; Flowers, C.R. Optimal disease surveillance strategies in non-Hodgkin lymphoma. Hematol. Educ. Progr. 2014, 2014, 481-487. [CrossRef]

36. Lindgaard, K.; Riisgaard, L. Validation of ultrasound examinations performed by general practitioners. Scand. J. Prim. Health Care 2017, 35, 256-261. [CrossRef] [PubMed] 